\title{
USO DE COBERTURAS COMESTÍVEIS EM FRUTAS E HORTALIÇAS: UMA REVISÃO DE LITERATURA
}

\author{
Nohora Vélez Carvajal ${ }^{1}$ \\ Patricia Alvarez Cabanez ${ }^{2}$ \\ Khétrin Silva Maciel ${ }^{3}$ \\ José Carlos Lopes ${ }^{4}$
}

Resumo: Devido à crescente necessidade no aproveitamento da produção de frutas e hortaliças, vem-se desenvolvendo tecnologias para prolongar sua vida pós-colheita; somado a isto, também existe o interesse de usar tecnologias de baixo custo e que não tenham efeitos negativos para o ambiente nem à nutrição humana. Dentro destas tecnologias encontra-se o uso de coberturas comestíveis. Assim, objetivou-se apresentar estudos recentes da aplicação de coberturas comestíveis em frutas e hortaliças, mostrando o efeito destas sobre sua a qualidade e duração da vida pós-colheita. Os critérios de inclusão de trabalhos utilizados foram: publicações recentes; que retratavam o assunto em questão; que abordavam as palavras chaves biofilmes, polissacarídeos, lipídios e proteínas. Através desta pesquisa pode-se concluir que é necessário continuar com o estudo do uso de diferentes coberturas comestíveis na pós-colheita de frutas e hortaliças, em função do cultivar e o método utilizado na sua aplicação; procurando matérias que sejam de fácil consecução e baixo custo, que possam ser utilizadas individualmente ou em combinação com diferentes formulações.

Palavras-chave: Biofilmes; Películas; Polissacarídeos; Lipídios; Proteínas.

\footnotetext{
1 Doutorado em Produção Vegetal / Universidade Federal do Espírito Santo - Centro de Ciências Agrárias e Engenharias, Brasil. E-mail: nora_velez@yahoo.com.

2 Doutorado em Produção Vegetal / Universidade Federal do Espírito Santo - Centro de Ciências Agrárias e Engenharias, Brasil. E-mail: patriciacabanez@gmail.com.

3 Doutorado em Produção Vegetal / Universidade Federal do Espírito Santo - Centro de Ciências Agrárias e Engenharias, Brasil. E-mail: khetrinmaciel@gmail.com.

4 Professor do Departamento de Produção Vegetal / Universidade Federal do Espírito Santo - Centro de Ciências Agrárias e Engenharias, Brasil. E-mail: jcufes@bol.com.br.
} 